\title{
WAVE LOADS ON EXPOSED JETTIES: DESCRIPTION OF LARGE SCALE EXPERIMENTS AND PRELIMINARY RESULTS
}

\author{
Luca Martinelli' ${ }^{1}$, Alberto Lamberti ${ }^{1}$, Maria Gabriella Gaeta ${ }^{1}$, \\ Matteo Tirindelli ${ }^{2}$, John Alderson ${ }^{3}$, Stefan Schimmels ${ }^{4}$
}

\begin{abstract}
The large scale experiments described in this paper were carried out at the Large Wave Flume (GWK, Große Wellenkanal) in Hanover (Germany). The research team included Universities of Bologna (IT), Edinburgh (UK), Southampton (UK), Plymouth (UK), HR Wallingford (UK) and Coast \& Harbor Engineering Inc (USA). Waveinduced loads on close-to-prototype scale jetties were measured, with particular attention to scale effects due to air content in water. The aim of the paper is to present the tests, describe the impact process and give preliminary results concerning uplift loads.
\end{abstract}

Keywords: large-scale experiments, jetty, wave force, venting, impacts.

\section{INTRODUCTION}

Jetties and off-shore platforms cannot easily be placed so high above the mean sea level that they are never reached by the waves. Waves hitting the front and the soffit or the deck apply a horizontal and a vertical load. In some cases, mainly dependent on the wave shape and velocity, severe impacts may occur producing damages as documented for instance by Shepsis et al., (2007).

Most of the scientific work dealing with impacts on jetties (i.e. Bea et al., 2001) is motivated by the severe subsidence ( $9 \mathrm{~m}$ until now) of the platform Ekofisk. The problem has become more general nowadays, due to the ocean level rising caused by global climate change, that increases deck exposure to wave attacks (the subsidence has the same effect as the mean water level rising).

In 2002, the absence of guidelines for the evaluation of the impact loads on jetties encouraged a joint project between HR Wallingford, Universities of Bologna and Rome. Small scale tests carried out in one of HR Wallingford (HRW) flumes provided measurements of wave loads on a jetty schematized with a frame of beams and decks (Tirindelli et al., 2002; Tirindelli, 2004; Cuomo et al., 2007).

The design guidelines derived by those experiments did not satisfactorily solve the problem of upscaling the tested results to prototype dimensions and motivated more testing at larger scale. Impulsive events like wave slam onto deck or beam elements necessarily involve compression over short durations of air entrained into the wave, which has the effect of a reduction of impact pressures (forces). This process does not scale completely neither by Froude nor by Cauchy laws, with the different phases of the compression/expansion processes scaling differently.

The over-estimation of impulsive events obtained by using Froude law to scale model data is the consequence of a combination of factors:

- air content in sea water at prototype scale is significantly higher than in fresh water at model scale; air acts as a cushion reducing impulsive peak pressures and increasing their duration;

- compression of air in the air/water mixture, particularly at prototype scale, is a highly non linear process predominantly controlled by the atmospheric pressure, that does not scale down in the model;

- model structures are stiffer than prototype ones; in general, this is rarely taken into account and little attention is paid to properly selecting material and structural stiffness when designing the models to be tested.

The difference in the air entrainment processes between large and small model scales was addressed by a FP6 research project in the framework of the Integrated Infrastructure Initiative HYDRALAB III - access to large scale laboratories - involving Universities of Bologna (IT), Edinburgh (UK), Southampton (UK), Plymouth (UK) and the Coast \& Harbor Engineering Inc (USA), see Lamberti et al. (2010a). The new tests basically reproduced the ones carried out in 2002 (quoted above) in a scale 5 times greater.

\footnotetext{
${ }^{1}$ DICAM, Bologna University, v.le Risorgimento 2, 40136 Bologna, Italy

${ }^{2}$ Coast and Harbour Engineering Inc., 155 Montgomery Street, Suite 608, San Francisco, CA 94104, USA

${ }^{3}$ HR Wallingford Ltd., Howbery Park, Wallingford, OX10 8BA, United Kingdom

${ }^{4}$ ForschungsZentrum Küste, Hannover, Germany
} 


\section{THE TESTS}

Facility

Tests were carried out in the period August-September 2009 (12 weeks access) at the GroßeWellen Kanal of the ForschungsZentrum Küste (FZK) in Hanover, DE (www.fzk-nth.de/277.htm). The wave flume is $309 \mathrm{~m}$ long, $7 \mathrm{~m}$ high and $5 \mathrm{~m}$ wide (Fig. 1).

The wave generator paddle is a mixed piston type and flap type (the upper part can rotate a limited amount). Only the piston-type movements are used. It is equipped with 8 pumps for a total of $880 \mathrm{~kW}$.

The existing software is capable of producing regular waves up to about $2 \mathrm{~m}$ (for periods around 5 $\mathrm{s}$ ), irregular waves and wave groups that focus at the desired location into a single wave of virtually unlimited height (i.e. only limited by depth). Non-linear wave theory is used to propagate the components of the focused wave, that appears very accurate especially for long periods.

It was possible to generate user-defined wave signals, and specifically short sequences which allowed to produce a high focused wave at a given location embedded in an irregular wave train of desired spectrum.

The existing active wave absorber of the paddle was always used. Replication of irregular signals produced exactly the same water elevation even in presence of breakers against the structure with high reflectivity.

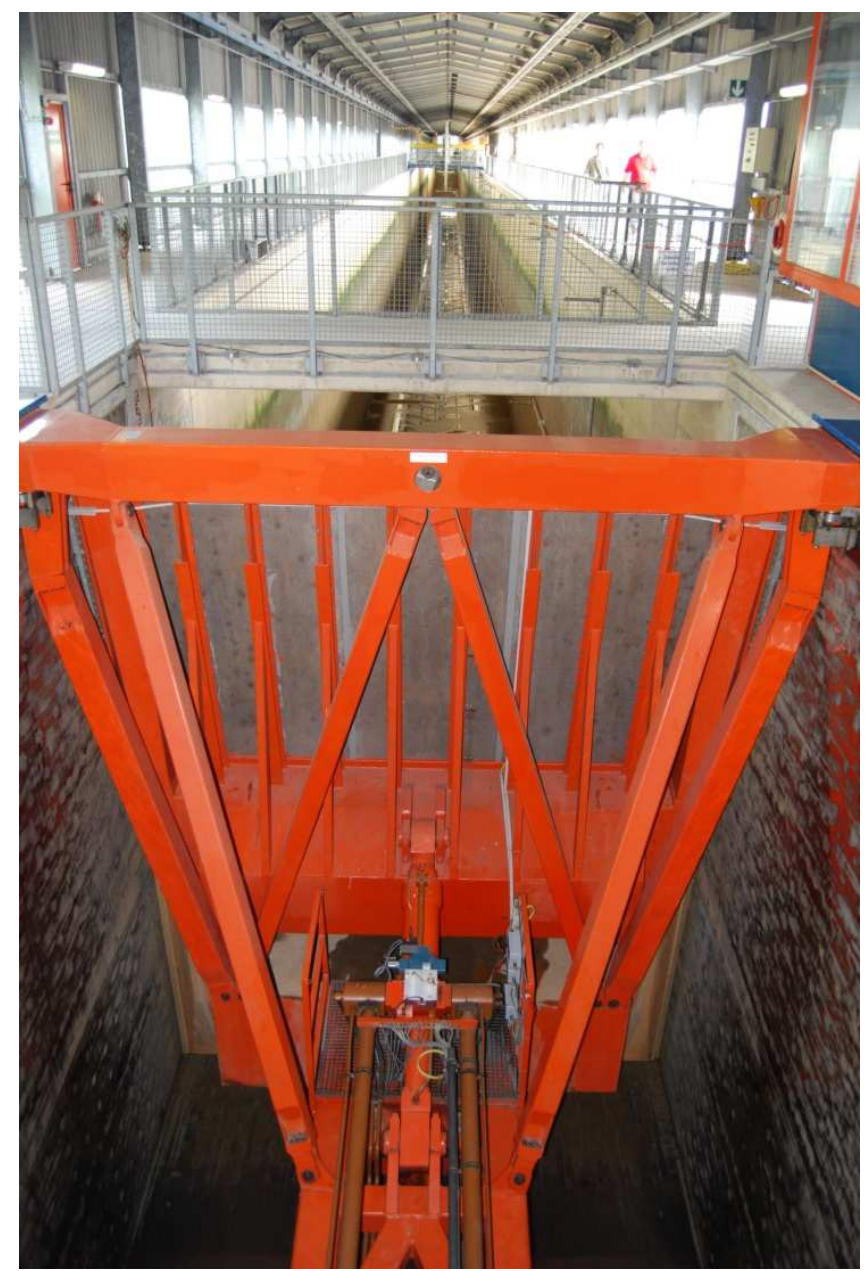

Figure 1. The flume and the $5.0 \times 7.0 \mathrm{~m}$ wave maker of the GWK.

\section{The tested structure}

The tested structure is meant to be a typical cross section of a long jetty. Rather than holding it with piles, that affect the local hydrodynamics, the structure is suspended to an upper rigid framework weighting approximately 5 tons (Figure 2). 
The tested section of the jetty (Figure 3), made of wood, is $0.2 \mathrm{~m}$ thick, $1.5 \mathrm{~m}$ wide and $3.8 \mathrm{~m}$ long. The deck is divided into three cells by two longitudinal and three transversal beams, also made of wood. The beam rectangular cross section is $20 \mathrm{~cm} \times 20 \mathrm{~cm}$ and therefore the total thickness of the structure is $40 \mathrm{~cm}$.

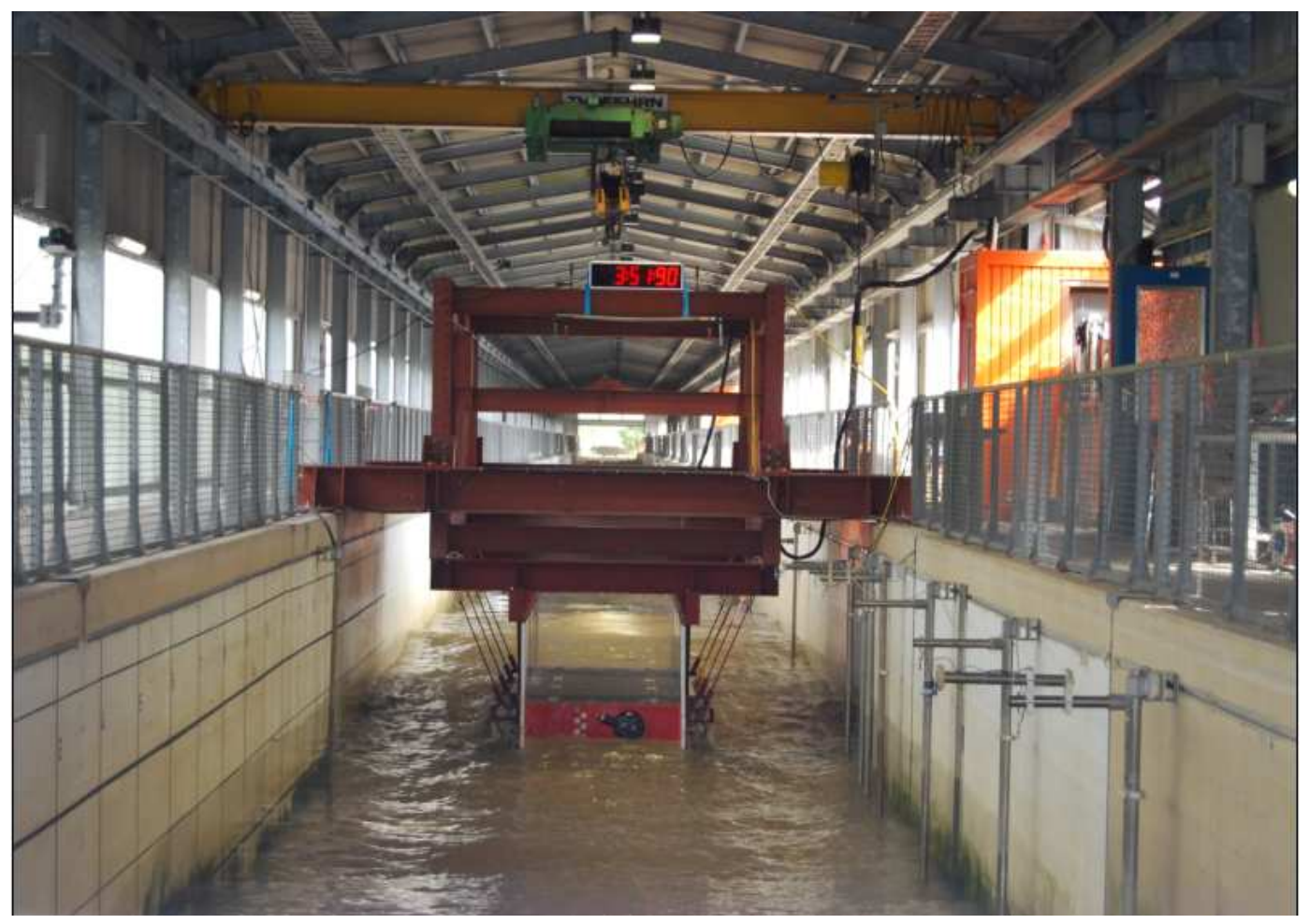

Figure 2. The rigid steel framework holing the jetty from above (the wave is just touching the deck soffit).

Three configurations are tested:

- Beams up: the flat part of the deck is placed downward, facing the water (Fig. 4, left).

- Beams down, closed vents. The deck is turned upside down so that the soffit is divided into three cells; during the impact, a cushion of air is trapped in each cell, confined by the lateral beams (Fig. 4, right).

- Beams down, open vents (Fig. 5). At the corners of the bays, 4 holes with diameter $4 \mathrm{~cm}$ and $1 \mathrm{~cm}$ are opened.

The wave attacks were characterized by $\mathrm{Hs}$ in the range $0.5 \mathrm{~m}-1.1 \mathrm{~m}$ and $\mathrm{Tp}$ in the range $2.8 \mathrm{~s}-6.7 \mathrm{~s}$.

\section{Bottom view}

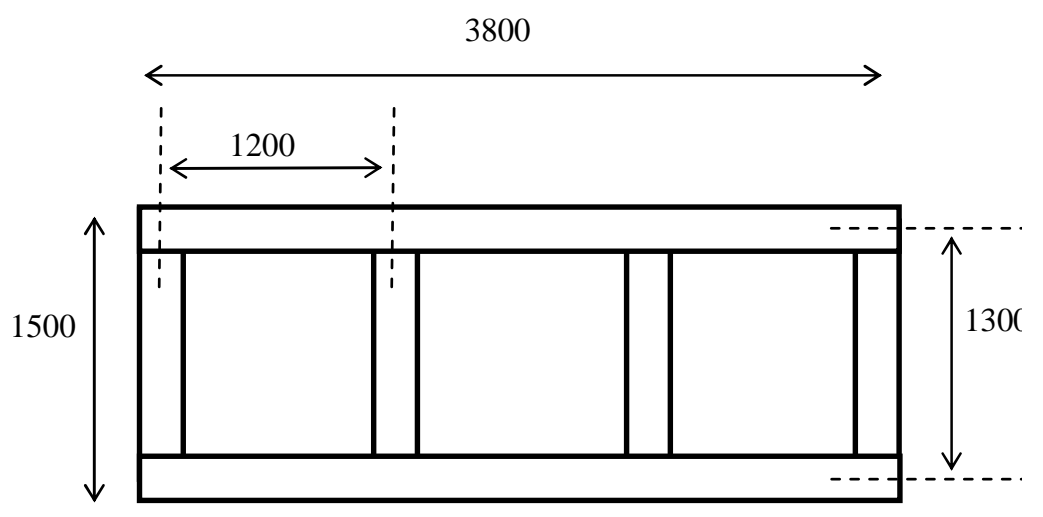

Figure 3. Tested section of the jetty. 


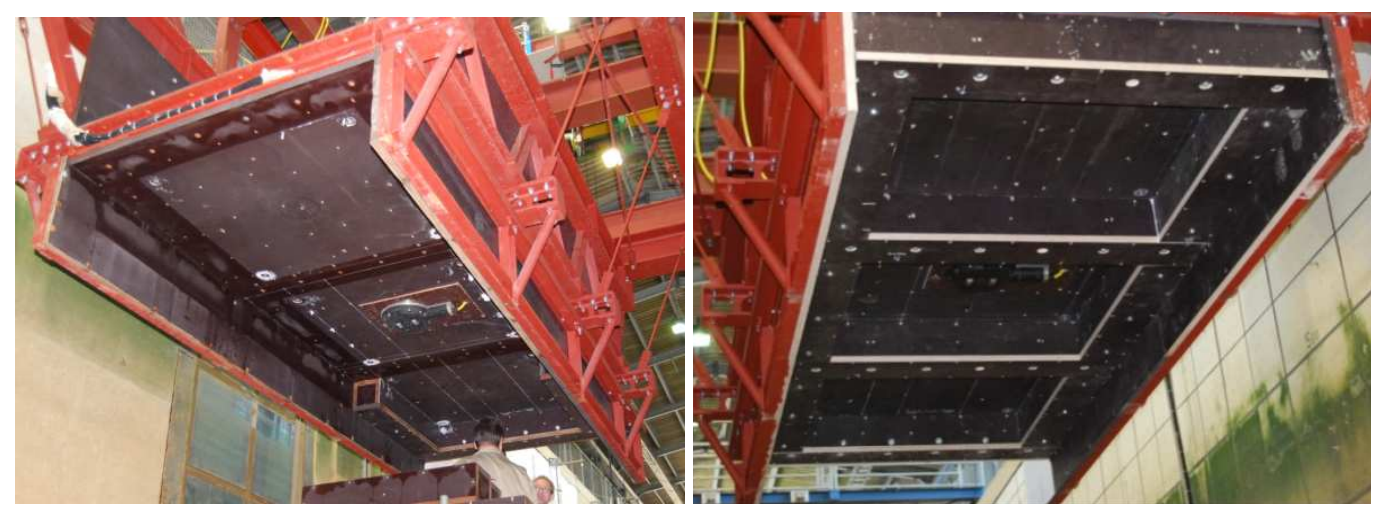

Figure 4. Left: Configuration beams up (the soffit of the deck is flat). Right: Configuration beams down.

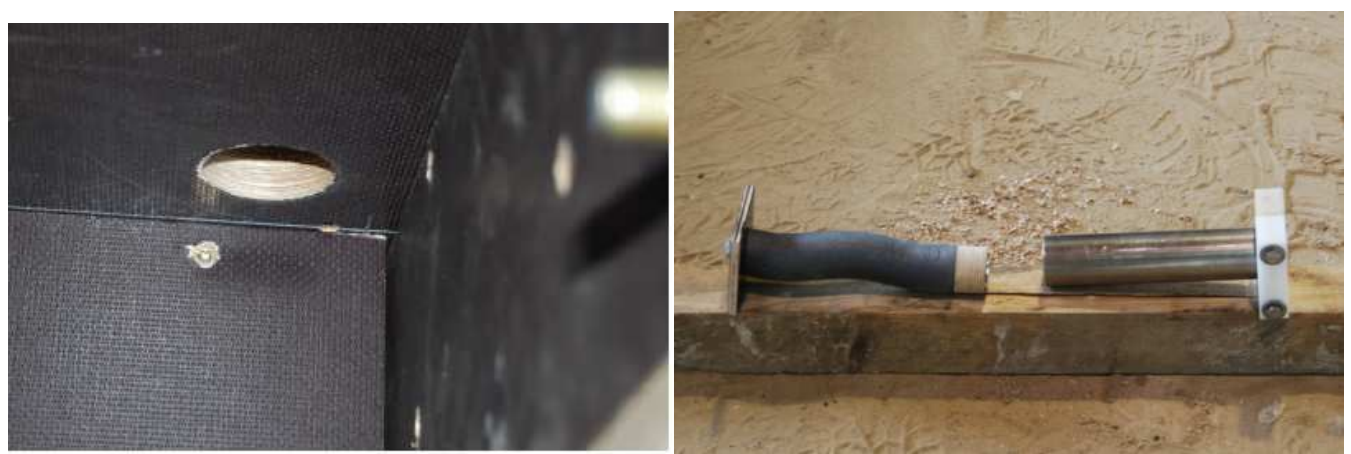

Figure 5. Details of the venting holes.

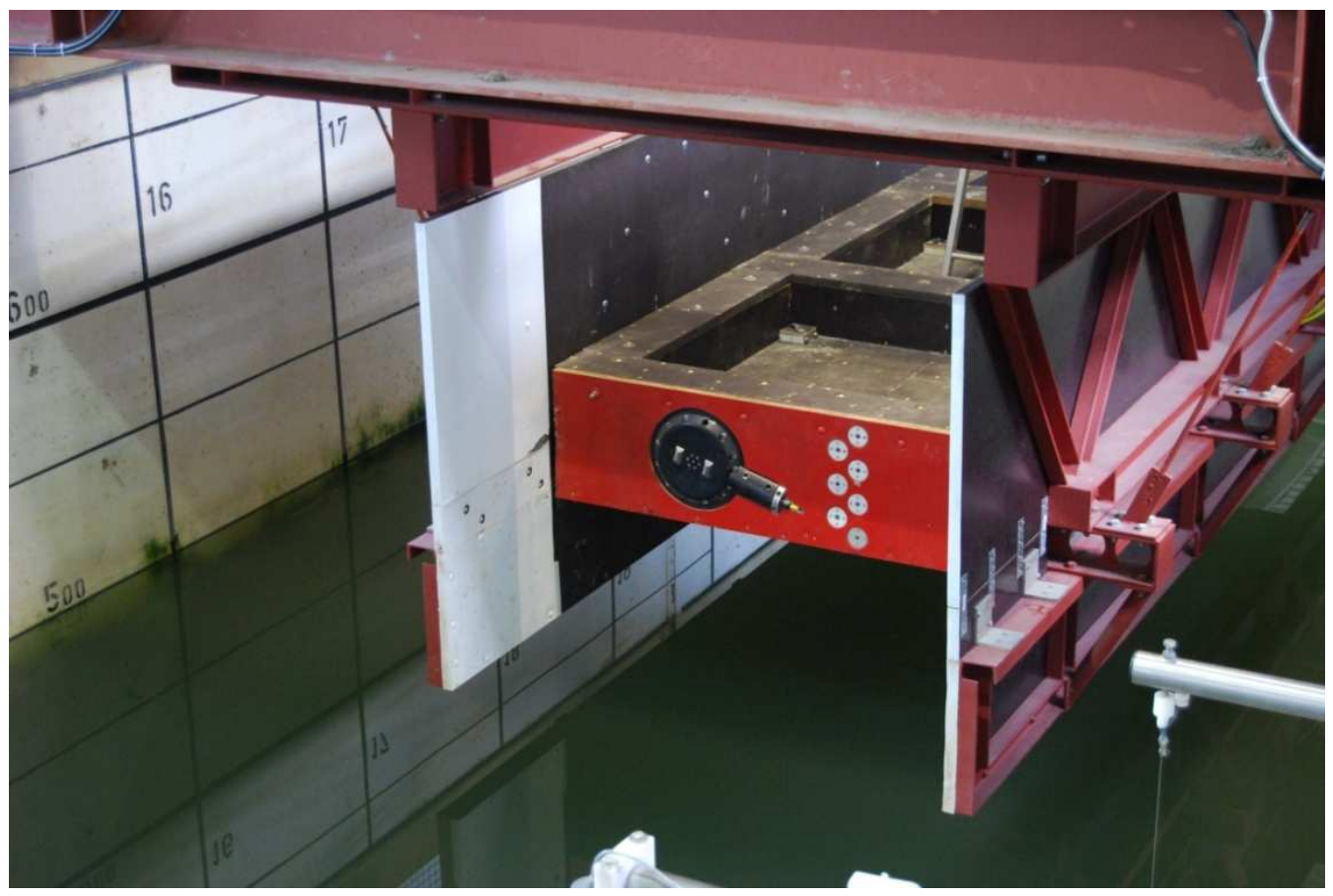

Figure 6. Lateral confinement. 
For each configuration, the wave sequence was repeated to account for:

- Two values of water depths $d: 4 \mathrm{~m}$ and $5 \mathrm{~m}$.

- Three values of total deck clearance $c: 0.05 \mathrm{~m}, 0.4 \mathrm{~m}, 0.8 \mathrm{~m}$. The clearance is computed starting from the lower part of the structure and not the deck soffit, so that for the beam down configuration, the tested suffit clearance is $0.2 \mathrm{~m}$ higher than $\mathrm{c}$.

In order to laterally confine the deck, two vertical walls are placed at the sides of the structure (Figure 6). The obtained lateral confinement is not complete. In fact, also the central section tested in the small scale tests (Tirindelli, 2004) is not fully confined.

\section{Instrumentation}

Instrumentation includes typical resistive wave gauges (WGs), fixed in position (they cannot be raised). They are usually calibrated only during the filling/emptying of the flume.

WGs are placed $10 \mathrm{~cm}$ from the wall, along the flume. Table 1 lists the longitudinal co-ordinate $s$ of the wave gauges ( $s$ is 0 at the wavemaker). Four more gauges are placed by the wave generator and are not listed.

\begin{tabular}{|l|c|c|c|c|c|c|c|c|c|c|}
\hline \multicolumn{10}{|c|}{ Table 1. Position of wave gauges along the wave flume (starting from the generator) } \\
\hline WP n $^{\circ}$ & $\mathbf{1}$ & $\mathbf{2}$ & 3 & $\mathbf{4}$ & $\mathbf{5}$ & $\mathbf{6}$ & $\mathbf{7}$ & $\mathbf{8}$ & $\mathbf{9}$ & $\mathbf{1 0}$ \\
$\mathrm{s}(\mathrm{m})$ & 10,00 & 20,00 & 30,00 & 40,00 & 50,00 & 51,90 & 55,20 & 60,00 & 70,00 & 80,00 \\
\hline $\mathrm{WP} \mathrm{n}^{\circ}$ & $\mathbf{1 1}$ & $\mathbf{1 2}$ & $\mathbf{1 3}$ & $\mathbf{1 4}$ & $\mathbf{1 5}$ & $\mathbf{1 6}$ & $\mathbf{1 7}$ & $\mathbf{1 8}$ & $\mathbf{1 9}$ & $\mathbf{2 0}$ \\
$\mathrm{s}(\mathrm{m})$ & 90,00 & 100,00 & 110,00 & 120,00 & 130,00 & 140,00 & 150,00 & 160,00 & 161,90 & 165,20 \\
\hline $\mathrm{WP} \mathrm{n}^{\circ}$ & $\mathbf{2 1}$ & $\mathbf{2 2}$ & $\mathbf{2 3}$ & $\mathbf{2 4}$ & $\mathbf{2 5}$ & $\mathbf{2 6}$ & $\mathbf{2 7}$ & $\mathbf{2 8}$ & & \\
$\mathrm{s}(\mathrm{m})$ & 170,00 & 180,00 & 190,00 & 200,00 & 210,00 & 220,00 & 230,00 & 240,00 & & \\
\hline
\end{tabular}

Wave pressures on the front face (Figure 6b) and bottom deck surface (Figure 6a) were measured by a set of 24 pressure transducers. Pressure cells are of the integrated silicon strain gauge bridge type, model Druck, PDCR 830 and sampled pressure in the range of 5 and 10 bar. The natural frequency in the range $28-360 \mathrm{kHz}$. Accuracy is $0.1 \%$ of full scale. Negative pressures are measured as well. The high sampling capacity is used to measure impact pressures with logging frequency of $4 \mathrm{kHz}$ for each channel. Some tests are also simultaneously acquired at $10 \mathrm{kHz}$.

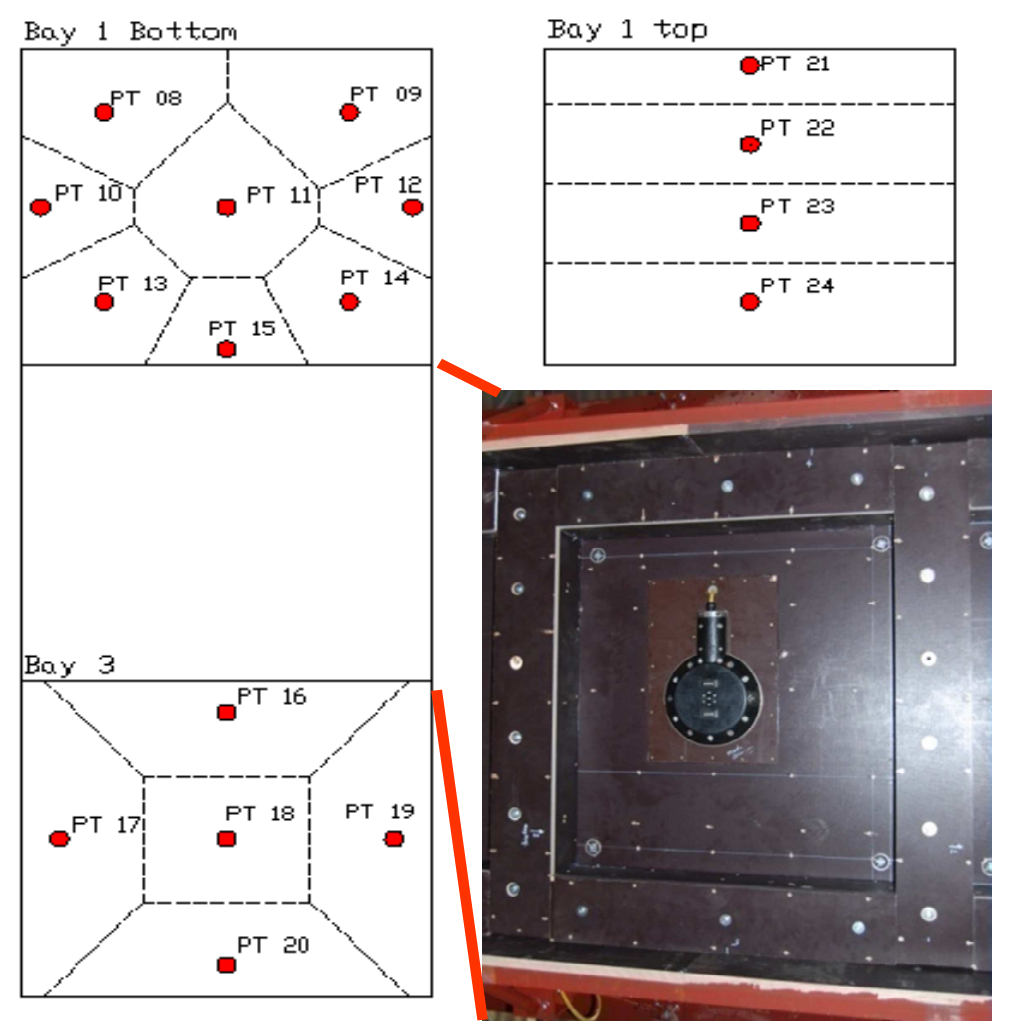

Fig. 6a. Position of pressure gauges under bays 1,2 and 3 and above bay 1 , and area of influence. 

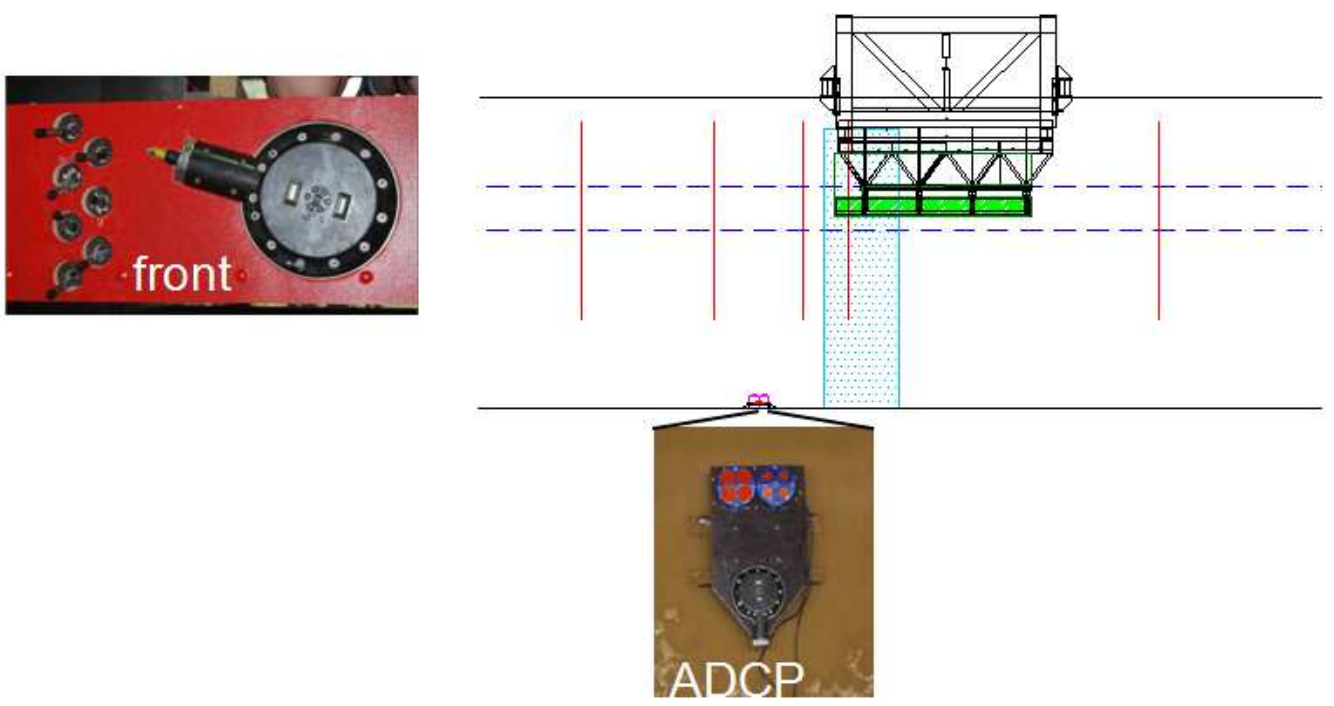

Figure 6b. Position of pressure gauges and PAU on the front deck and of the ADCPs

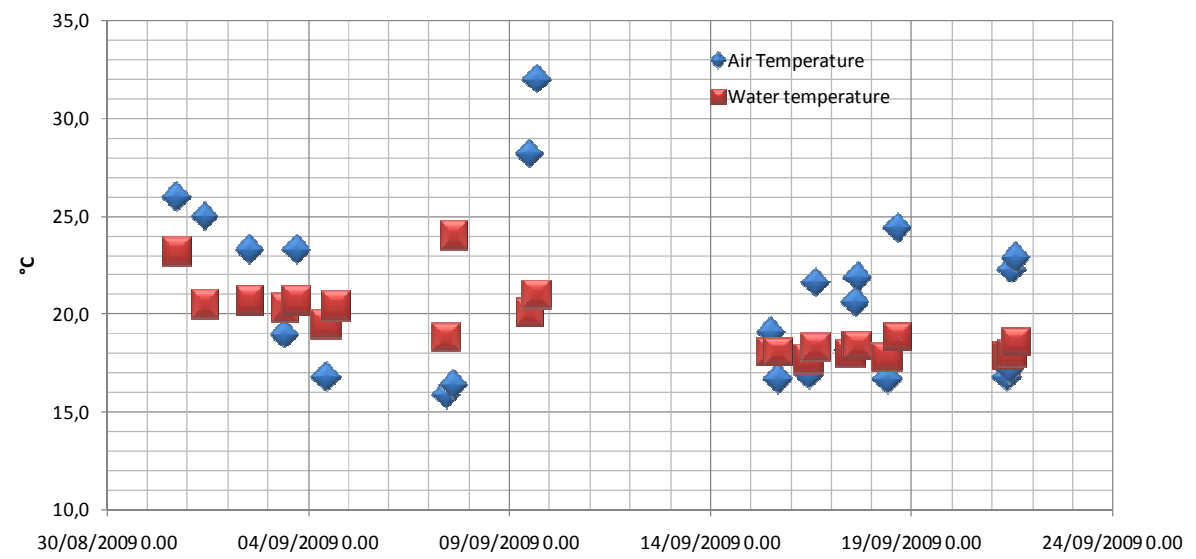

Fig. 7a. Air and Water temperature.

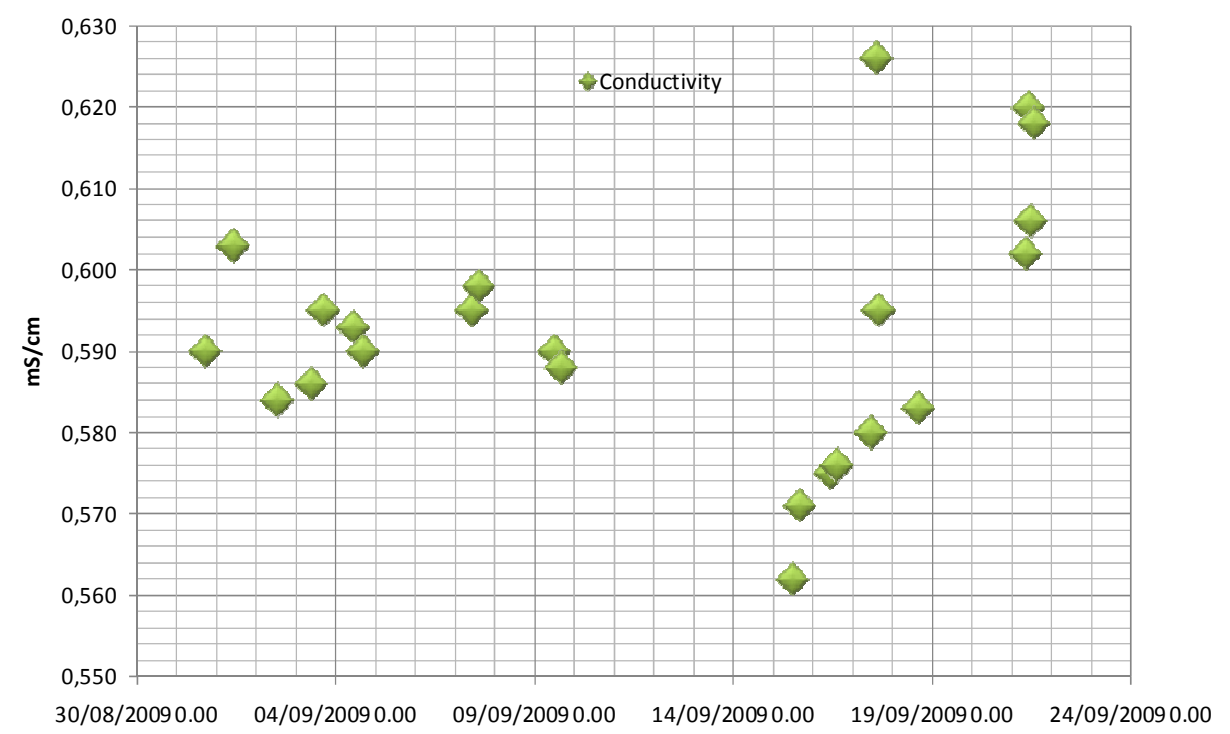

Fig. 7b. Water conductivity at rest. 
Two normal speed video-cameras were also used to document the impacts.

Some key instruments were supplied by the research groups: Acoustic Doppler Current Profilers ADCP (by Bologna University) and Pressure Aeration Units PAU (by Plymouth), both in Figure 6b, and a Wave Tape (by Edimburgh University):

-ADCPs n.1 and n.2, RDI instrument, 600 and $1200 \mathrm{kHz}$

-PAU n.1, pressure and aeration (submergible)

-PAU n.2, pressure and aeration (cannot go under water)

-PAU n.3, pressure only (submergible)

-Wave Tape (invented by Brian Sellar)

The PAUs measure the water conductivity and by this the air content of water.

Similarly, the 2 ADCPs at different frequencies can recognize the air content in water and distinguish the bubble size. The basic principle of the measurement system is based on the property of the scattered powers, that is proportional to the number of bubbles and is function of the ratio between bubble diameter and length of the generated sound wave. By comparing the response of the two instruments, the bubble diameter and concentration can be determined.

Measurements of water and atmosphere temperatures (Figure 7a) and of water conductivity (Figure 7b) were also carried out frequently during each test day, up to 4 times.

Four acquisition systems were used:

-The basic one operated by Daisy software, used to log all instruments at $4 \mathrm{kHz}$.

- An experimental system with software Preston was used in some cases to duplicate the acquisition of the pressure signals at $10 \mathrm{kHz}$. The triggering signal caused some noise in the other channels, and is therefore shut down after a few seconds.

- The acquisition system for the two ADCPs, used only for the beams down configuration, with low frequency $(50 \mathrm{~Hz})$, untriggered.

-The acquisition system for the wave tape, used for approximately 30 tests, with low frequency, untriggered.

\section{Wave conditions and test sequence}

The tested conditions (Table 2) are meant to reproduce regular and irregular (Jonswap, spectrum with peak enhancement factor 3.3) wave attacks tested in the small scale experiments carried out at HRW (after up-scaling).

\begin{tabular}{|c|c|c|c|c|c|c|c|}
\hline \multicolumn{7}{|c|}{ Table 2. Series of tested wave conditions (example for $\mathbf{d = 4 . 0 0} \mathbf{~ m , ~} \mathbf{c = 0 . 4 0} \mathbf{~ m}$ ) } \\
\hline Type & $\begin{array}{c}\text { Peak wave } \\
\text { period } \\
T p, \mathrm{~s}\end{array}$ & $\begin{array}{c}\text { Significant } \\
\text { wave height } \\
\text { Hs, } \mathrm{m}\end{array}$ & $\begin{array}{c}\text { Wave length } \\
\text { Lp, } \mathrm{m}\end{array}$ & $\begin{array}{c}\text { Expected } \\
\text { max crest } \\
\text { height, } \mathrm{m}\end{array}$ & $\begin{array}{c}\text { Max Hor. } \\
\text { Velocity at } \\
\text { crest, } \mathrm{m} / \mathrm{s}\end{array}$ & $\begin{array}{c}\text { Max Vert. } \\
\text { Velocity at } \\
\text { clearance, } \\
\mathrm{m} / \mathrm{s}\end{array}$ & $\begin{array}{c}\text { Max Hor. } \\
\text { Velocity at } \\
\text { clearance, } \\
\mathrm{m} / \mathrm{s}\end{array}$ \\
\hline Reg & 3,4 & 0,90 & 16,89 & 0,50 & 1,12 & 0,57 & 0,89 \\
\hline Reg & 6,7 & 0,90 & 40,35 & 0,56 & 0,99 & 0,43 & 0,67 \\
\hline Reg & 3,4 & 1,10 & 16,89 & 0,63 & 1,43 & 0,81 & 0,96 \\
\hline Reg & 5,6 & 1,10 & 32,99 & 0,68 & 1,24 & 0,66 & 0,70 \\
\hline Irr, J & 3,4 & 0,90 & 16,89 & 0,92 & 2,20 & 1,28 & 1,00 \\
\hline Irr, J & 4,5 & 0,90 & 24,90 & 0,93 & 1,89 & 1,08 & 0,82 \\
\hline Irr, J & 5,6 & 0,90 & 32,69 & 0,95 & 1,80 & 0,94 & 0,80 \\
\hline Irr, J & 6,7 & 0,90 & 40,35 & 0,99 & 1,80 & 0,66 & 0,88 \\
\hline Irr, J & 3,4 & 1,10 & 17,11 & 1,17 & 2,88 & 1,50 & 1,10 \\
\hline Irr, J & 4,5 & 1,10 & 25,13 & 1,18 & 2,44 & 1,30 & 0,87 \\
\hline Irr, J & 5,6 & 1,10 & 32,99 & 1,19 & 2,31 & 1,15 & 0,75 \\
\hline Focused & 3,4 & & 16,89 & 0,92 & 2,20 & 1,28 & 1,00 \\
\hline Focused & 4,5 & & 24,90 & 0,93 & 1,89 & 1,08 & 0,82 \\
\hline Focused & 5,6 & & 32,69 & 0,95 & 1,80 & 0,94 & 0,80 \\
\hline Focused & 6,7 & & 40,35 & 0,99 & 1,80 & 0,66 & 0,88 \\
\hline Focused & 3,4 & & 16,89 & 1,17 & 2,88 & 1,50 & 1,10 \\
\hline Focused & 4,5 & & 25,13 & 1,18 & 2,44 & 1,30 & 0,87 \\
\hline Focused & 5,6 & & 32,99 & 1,19 & 2,31 & 1,15 & 0,75 \\
\hline
\end{tabular}


In some cases, maximum wave height or attack duration becomes quite challenging for the wavemaker. It was therefore decided to select the highest waves and reproduce them with the focused wave techniques (Hunt, 2003). This would also allow to repeat the extreme loads and obtain a greater statistical description of the maxima. The main difference between impacts produced by irregular and focused waves is the air content of the water prior to the impact, that in the first case is the result of a presumably long sequence of breakers and in the second case is just the initial one.

In order to reduce this difference, the focused wave is embedded into an irregular train of 5 minutes. The focusing point is obtained with a trial and error procedure, the initial guess based on linear theory that anyway produced a fairly small error.

\section{Structure natural response}

The structure dynamics is investigated by means of two accelerometers placed within the first bay. One instrument, measuring the acceleration along the horizontal direction, does not record only on the overall jetty oscillations, but -unfortunately- also on the wooden vibrations. The other one, along the vertical direction, measures (beside the overall oscillations) the vibrations of the steel frame. The latter disturbances were approximately 5 times greater than the former ones.

Figure 8 shows the vertical acceleration of the deck (time history and Psd). The signal contains some power in absence of impacts (green line) which is also present during the impact (red line). In particular, two sharp peaks at 100 and $200 \mathrm{~Hz}$ are evident whose nature is still undetermined and could be of electronic origin. The impact certainly adds a vertical oscillation at $11 \mathrm{~Hz}$, which is also observed as synchronized vertical oscillations of same amplitude in the pressure signals. As a consequence, it is evident one of the modes of oscillations of the structure is vertical the vertical one, at $11 \mathrm{~Hz}$.

Figure 8 shows that the wave only adds one fraction of the power to the power spectral density curve. It is therefore interesting to observe the difference of the two curves, in order to isolate the effect of the impact. Figure 9 shows such difference for both accelerometers. It can be noticed that the horizontal spectrum is quite larger, typical of a wooden structure, whereas the vertical one shows sharp peaks, more typical of a rigid metallic frame.

Sharp peaks at 100 and $200 \mathrm{~Hz}$ are of difficult interpretation, since the $50 \mathrm{~Hz}$ component is missing.
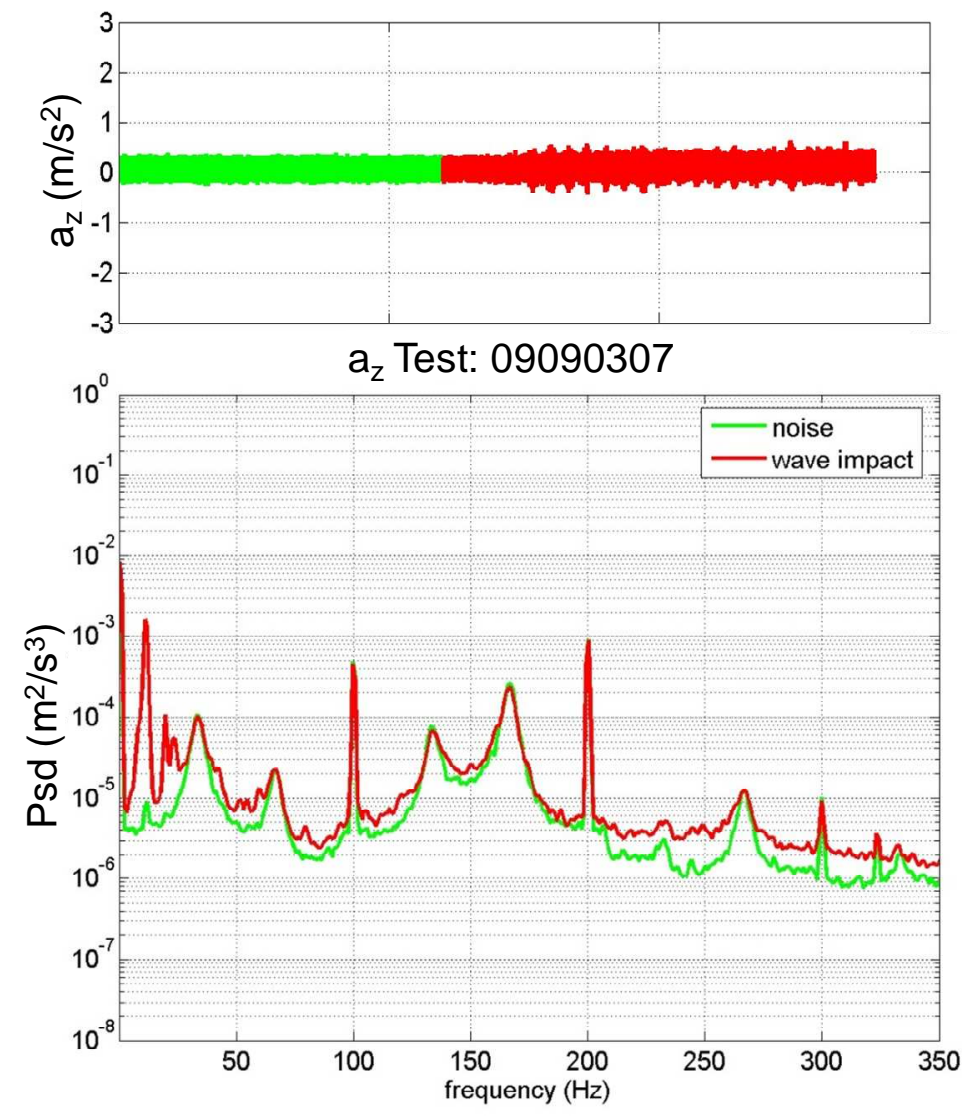

Figure 8. Accelerations of the structure measured in absence and in presence of wave impacts. 


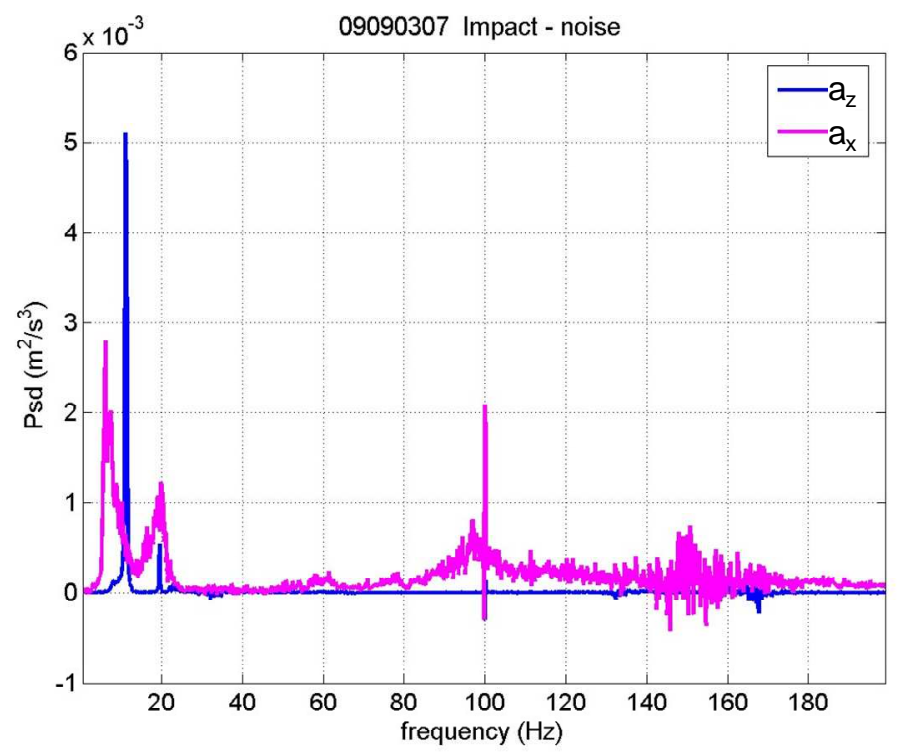

Figure 9. Psd of the component of the structure accelerations induced by the impact. Horizontal and vertical directions.

\section{RESULTS}

\section{Description of the impact process}

In order to understand the impact process in beam down configuration, a specific numerical simulation is presented in Figure 10. The Cobras2 model (Gaeta, 2009) is used, solving RANS equations in 2DV for water and compressible air, expressed in conservative form and using the volume of fluid approach to track the free surface.

The absolute value of the velocity and the pressure field in water and air are plotted in 5 consecutive instants, with time interval $1 \mathrm{~s}$. The simulated structure geometry reproduces the jetty cross section, and particularly the three bays.

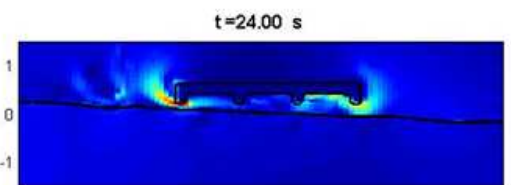

$t=25.00 s$

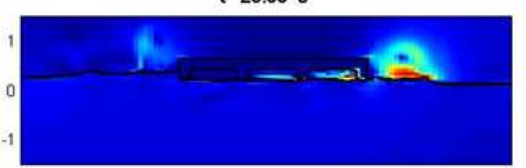

$t=26.00 s$

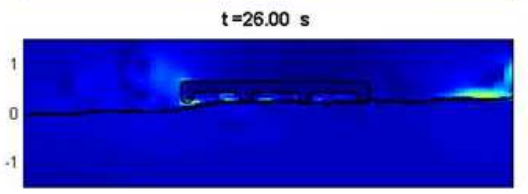

$t=27.00 s$

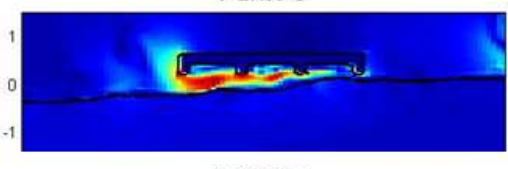

$t=28.00 \mathrm{~s}$

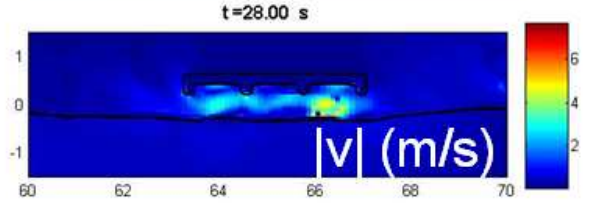

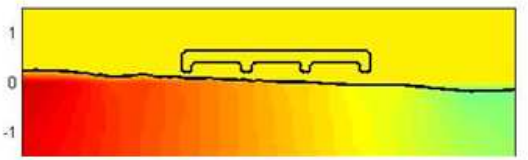
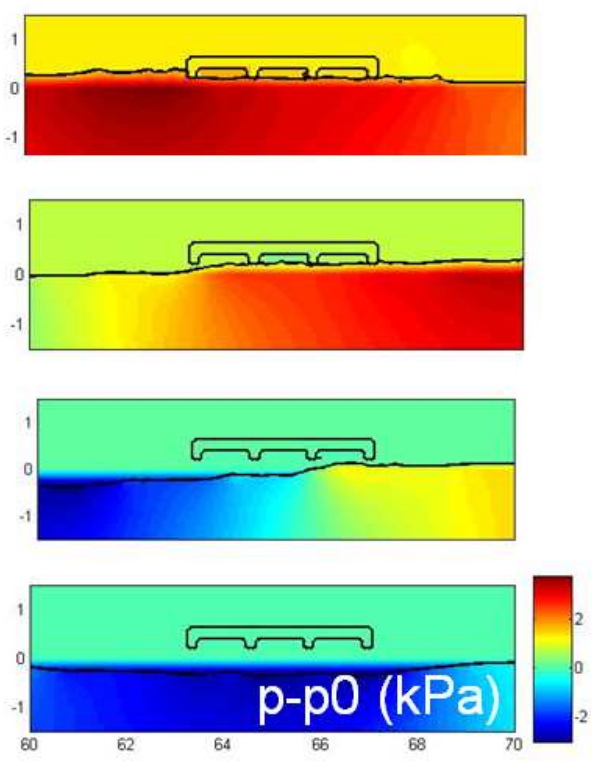

Figure 10. Absolute value of the velocity (left) and pressure field(right) of water and air, as the wave travels past the structure. From top to down, 5 instants are plotted with time interval $1 \mathrm{~s}$. 
In the first two snapshots at the top, corresponding to $t=24 \mathrm{~s}$, the wave approaches the deck and the air is forced to escape flowing both seaward and landward; at $\mathrm{t}=25 \mathrm{~s}$, the wave has already touched the front deck but air has not completely escaped under the cell: in the first two bays air is trapped and compressed, in the latter the air is still escaping backward. At $\mathrm{t}=26 \mathrm{~s}$, the wave is compressing the rear deck. At $\mathrm{t}=27 \mathrm{~s}$, air under the first bay is so decompressed that it is sucked from the front; at $\mathrm{t}=28 \mathrm{~s}$, the air pressure is almost stabilized but the velocity is greater than that of the wave due to turbulent effects.

\section{Logging frequency}

Choice of the logging frequency, $4 \mathrm{KHz}$ (in some case $10 \mathrm{KHz}$ ) was far greater than the required optimal, in order to study the importance of the frequency of acquisition for these kinds of tests.

Given the spatial resolution of pressure gauges used in these tests, $5 \mathrm{~cm}$, a $100 \mathrm{~Hz} \operatorname{logging}$ frequency is optimal. Of course, in order to avoid aliasing, a low-pass filter must be inserted before the acquisition system. This conclusion is argued in Martinelli et al. (2010, in Italian) and in Lamberti et al. (2010b): when the load is derived by pressure integration, the resolution in time and space must be related to each other to avoid misinterpretations. As a consequence, the incredibly large amount of stored data do not add much information to the load process. In fact, at $4 \mathrm{KHz}$, the spatial correlation between the pressure signals is significantly smaller than the transducers spacing and each pressure reading is only valid in the close proximity to the point of measurement. Measurements at $4 \mathrm{KHz}$ cannot be extended to the whole region between sensors: evaluation the spatial integral in these conditions results in a large overestimation of the force.

Lamberti et al. (2010b) show an example of constant unit load applied to the jetty, consisting of a sharp impulsive pressure peak of unit intensity moving with the convective velocity of the wave along the front face. The load is accurately measured by an array of pressure transducers only if a low-pass filter is applied, with cut-off frequency appropriate to the spatial interval. If, on the contrary, the cutoff frequency is too high, the integral of the pressures identifies non-existent peaks on the load, whose intensities are proportional to the logging frequency itself.

Data shown in the following are therefore down-filtered at $100 \mathrm{~Hz}$.

It is seen in a previous Section that the system dynamics response in the range $0-100 \mathrm{~Hz}$ seems to be affected only by the rigid body oscillation modes. It is therefore possible to reconstruct the applied load in the range $0-100 \mathrm{~Hz}$ by transforming the load signal with the inverse of the jetty dynamic response.

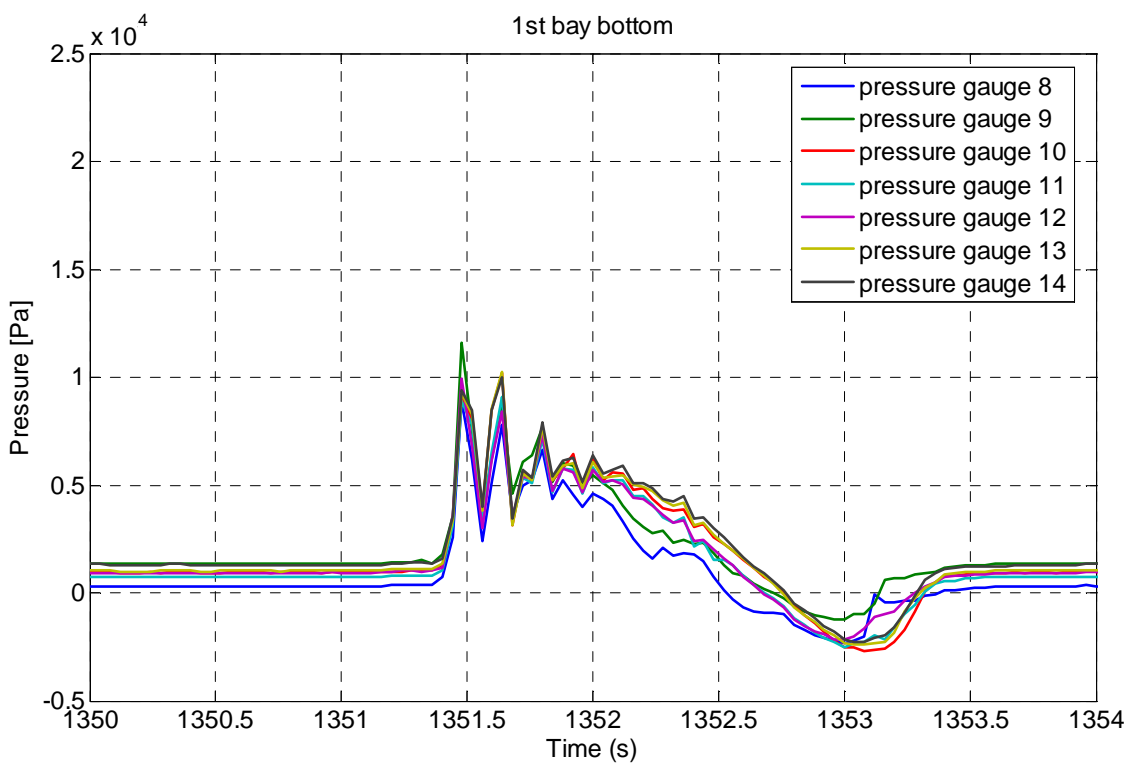

Figure 11. Test 09091803, Beams up, no venting, Irregular, $d=4 \mathrm{~m}, c=0.4 \mathrm{~m}, H_{\mathrm{s}}=0.9 \mathrm{~m}, T_{\mathrm{p}}=6.7 \mathrm{~s}$

Uplift

This section compares the measured uplift pressure on the first bay, for the three different configurations, with clearance $0.4 \mathrm{~m}$ and depth $4 \mathrm{~m}$.

The same wave sequences are considered: an irregular wave with $\mathrm{Hs}=0.9 \mathrm{~m}, \mathrm{Tp}=6.7 \mathrm{~s}$.

The acquisition system started before the wave generator and a visual procedure is used to shift in time the records so that a similar time origin is used for different tests with same wave conditions. 
Pressure signals in Figures 11-13 are relative to the same wave of the pseudorandom sequence.

Figure 11 shows the case of beams up (absence of venting). The pressure signals do not start from zero, since the offset has not yet been removed in this case. Just before instant $1351.5 \mathrm{~s}$, the deck is clearly hit by the wave and a $11 \mathrm{~Hz}$ oscillation is visible around a high mean value of order $5 \mathrm{kPa}$ (i.e. a water column of $0.5 \mathrm{~m}$ ). The oscillation soon decays whereas the steady component has a duration compared to half wave period. At $\mathrm{t}=1353 \mathrm{~s}$, a clear negative pressure is observed for all the channels. This feature, already anticipated for the beam down case, is the consequence of the water coming off the deck soffit.

Figure 12 shows tentatively the same wave hitting the structure in the beams down configuration, without venting. By comparing to Fig. 11, it is immediately evident to see that the pressure peak is quite higher, leading to a force that may be 2-3 times more intense. The pressure oscillations, possibly caused by the structure vertical movements, last longer. The time interval between maximum and minimum is the same, equal to $1.5 \mathrm{~s}$.

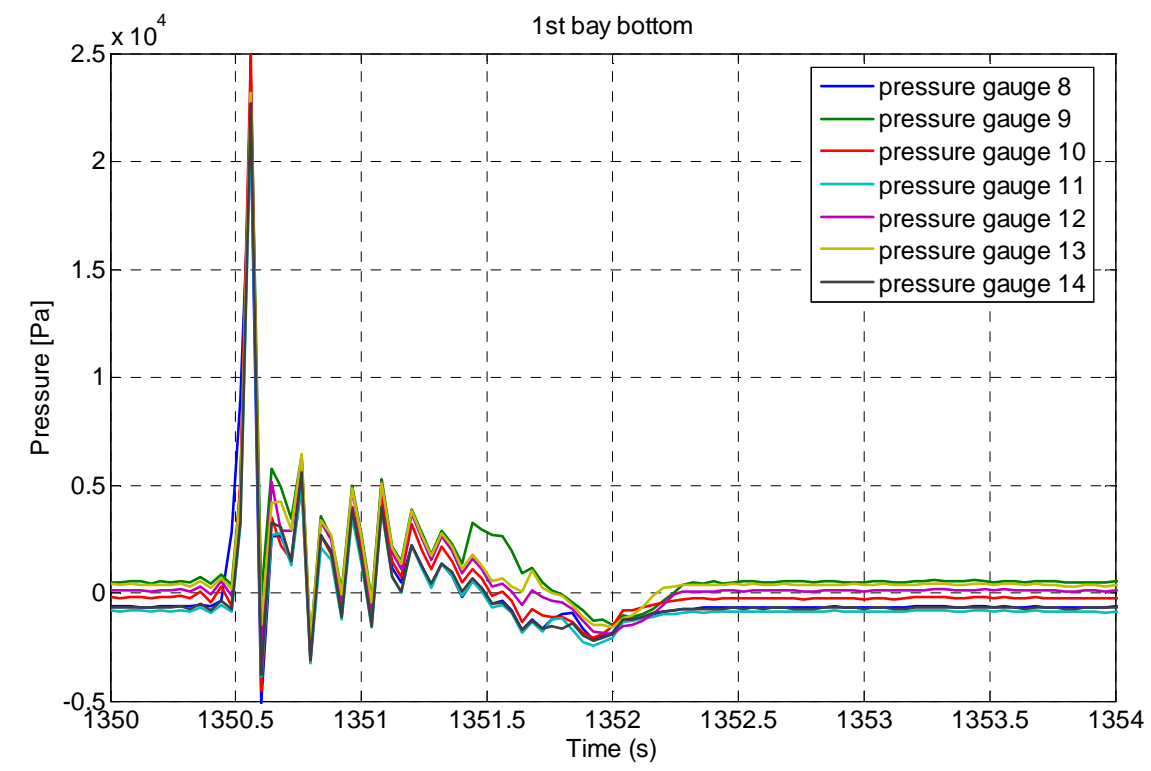

Figure 12. Test 09082711 , Beams down, no venting Irregular $d=4 \mathrm{~m}, c=0.4 \mathrm{~m}, H_{\mathrm{s}}=0.9 \mathrm{~m}, T_{\mathrm{p}}=6.7 \mathrm{~s}$

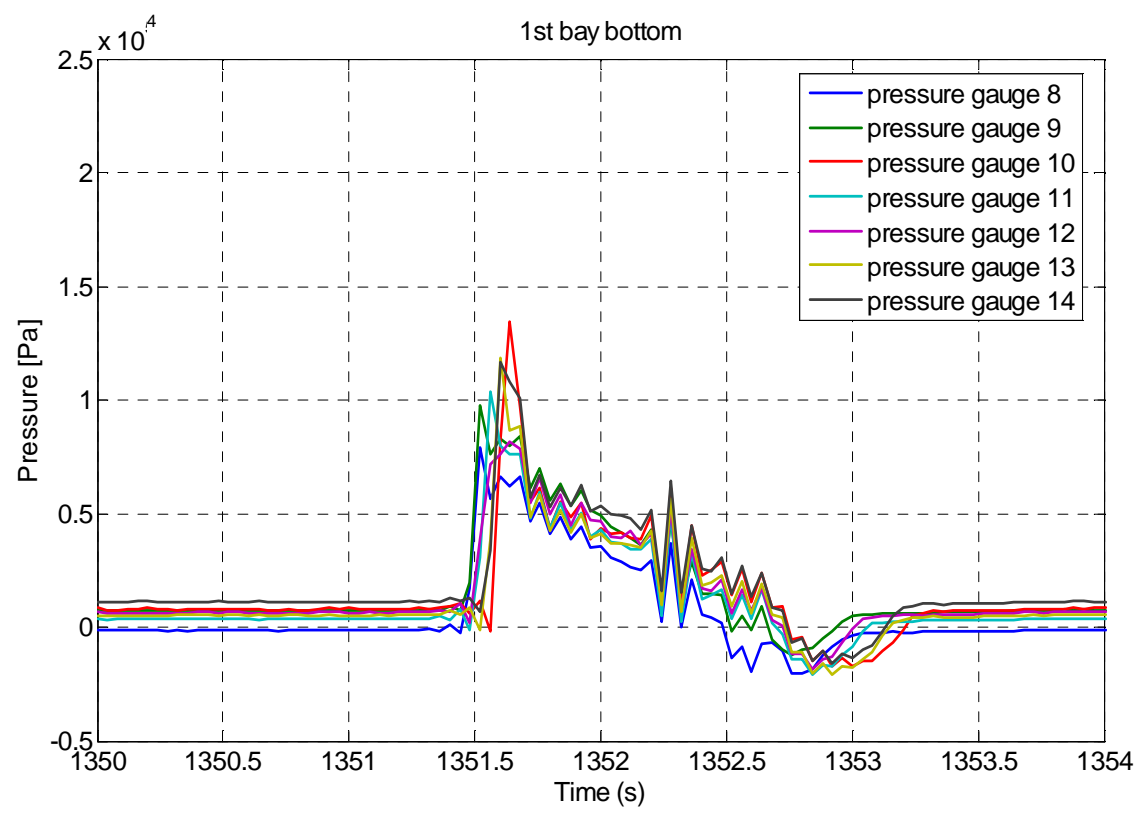

Figure 13. Test 09090907, Beams down, venting, Irregular, $d=4 \mathrm{~m}, c=0.4 \mathrm{~m}, H_{\mathrm{s}}=0.9 \mathrm{~m}, T_{\mathrm{p}}=6.7 \mathrm{~s}$ 
Figure 13 shows the structure in the beams down configuration with venting. The venting reduces the air cushion effect causing slightly higher force compared to the case in absence of venting, but still much lower forces than the beams up case. The pressure oscillations (previously ascribed to the structure vertical oscillations) are less pronounced and with a different pattern compared to the previous cases. This is reasonably due to the superposition of a different mechanism, the water escape through the vents, whose effect is to smooth the pressure oscillations. The time interval between maximum and minimum is reduced, $1.3 \mathrm{~s}$, possibly because in presence of venting the water can more easily came off the soffit.

Unfortunately it is difficult to compare the response to wave slamming since it was observed that, although the incident wave is apparently alike, the pressure measurements relative to the derived impacts may vary significantly.

\section{CONCLUSIONS}

Large scale tests were carried out in the period August-September 2009 at the GrosseWellen Kanal of the ForschungsZentrum Küste (FZK) in Hanover, DE (www.fzk-nth.de/277.htm).

Aim of the experiments was to investigate on the loads applied by waves on exposed jetties and, more specifically, on scale effects

Model geometry, tested configurations, instruments position and the structure dynamics are described in detail and will form a reference for future investigations.

The system eigenfrequancies and eigenmodes are studied, and in particular a $11 \mathrm{~Hz}$ vertical oscillations is recognized.

Based on the convective velocity of the wave, pressure data are low-pass filtered at $100 \mathrm{~Hz}$ and forces on the structure are obtained by spatial integration.

Initial analysis show that the vertical impact load process is inherently uncertain, but quite dependent on the venting and confinement conditions under the deck. The air cushion effect, studied also by means of a numerical model, tends to reduce the maximum uplift force.

\section{ACKNOWLEDGMENTS}

The experiment was partially supported by EU FP6 through the Integrated Infrastructure Initiative HYDRALAB III.

\section{REFERENCES}

Bea, R.G., R. Iversen and T. Xu (2001): Wave-in-Deck Forces on Offshore Platforms. J. Offshore Mechanics and Artic Eng., 123, 10-21.

Bull M.K. (1967): Wall-pressure fluctuations associated with subsonic turbulent boundary layer flow. J. Fluid Mech., 1967, 28 (4), 719-754.

Cuomo, G., M. Tirindelli and N.W.H. Allsop (2007): Wave-in-deck loads on exposed jetties, Coastal Engineering, 54(9), 657-679.

Gaeta, M.G. (2009): Two phase numerical model for coastal applications. Ph.D. Thesis, University of Bologna, $198 \mathrm{pp}$.

Hunt, A.C. (2003): Extreme waves, overtopping and flooding at sea defences, Ph.D. Thesis, Oxford Univ.

Lamberti A., L. Martinelli, M. Guerrero, G. Gaeta, W. Allsop, J. Alderson, M. Tirindelli, V. Shepsis, A.H. Rab, B. Sellar, T. Bruce (2010a): Large scale measurements of extreme wave loadings on exposed jetties, Proc. HYDRALAB III Joint User Meeting, Hannover, 45-48.

Lamberti A., L. Martinelli, G. Gaeta, M. Tirindelli, J. Alderson (2010b): Experimental spatial correlation of wave loads on front decks, submitted, J. of Hydraulic Research.

Martinelli L., A. Lamberti, M. G. Gaeta, M. Guerrero (2010): Sollecitazioni ondose su pontili a grande scala. parte 2: analisi delle forze, Proc Convegno di Idraulica e Costruzioni Idrauliche, IDRA, Palermo, in italian.

McConnell, K., N.W.H. Allsop and I. Cruickshank (2004): Piers, jetties and related structures exposed to waves: guidelines for hydraulic loadings, HR Wallingford, Wallingford, UK, 2004, ISBN 072773265X.

Shepsis, V., S. Fenical, J. Bardi and M. Tirindelli. (2007): Reconstruction of Cozumel's international cruise terminal after hurricane Wilma, Proc. Coastal Structures 2007, 2000-2010.

Tirindelli, M. (2004): Wave-induces forces on maritime structures, Ph. D Thesis, Politecnico di Milano.

Tirindelli, M., G. Cuomo, N.W.H. Allsop and A. Lamberti (2002): Wave-in-deck forces on jetties and related structures, Proc. ISOPE 2003, Honolulu, electronic format. 